\title{
Conservation of Mediterranean oak woodlands: understorey dynamics under different shrub management.
}

\author{
Cátia Canteiro • Carla Pinto-Cruz • M. Paula Simões • Luiz Gazarini \\ Agroforest Syst (2011) 82:161-171
}

\begin{abstract}
The effect of experimental disturbances on the dynamics of a shrub community was studied on a'Montado' ecosystem, in southern Portugal. The evolution of the community physiognomy, composition and diversity were monitored after shrub clearing followed by biomass removal, deposition on soil surface and incorporation with the soil, over a 9-year period. Maximum shrub density was recorded in the first year after the disturbances, excepting in mulched plots which showed the greatest number of individuals 1 year later. The increment of shrub leaf biomass was very fast in the first 3 years, whereas wood production was slower but occurred along the whole study period. At the end of the study, leaf and wood biomass was still significantly lower than in the predisturbance situation. The variation pattern of leaf area index was similar to that of leaf biomass. The evolution of total plant cover and diversity was similar across treatments. The highest species richness and diversity were recorded 2 years after cutting, decreasing afterwards with the increasing dominance of shrubs. Thus it seems likely that, although a 9 year period is too short for these communities to reach steady equilibrium, they are very resistant and resilient to disturbances, as regeneration was fast and vegetation dynamics was not influenced by differences among treatments. We can conclude that shrub clearing promotes biodiversity and the time of permanence of shrub patches depends on the particular goal we want to achieve.
\end{abstract}

